\title{
Synthesis of push-pull chromophores by the sequential [2 +2] cycloaddition of 1-azulenylbutadiynes with tetracyanoethylene and tetrathiafulvalene
}

\author{
Taku Shoji, ${ }^{*}{ }^{a}$ Shunji Ito, ${ }^{b}$ Tetsuo Okujima, ${ }^{c}$ and Noboru Morita ${ }^{d}$ \\ 5 Received (in $X X X, X X X)$ Xth $X X X X X X X X X 20 X X$, Accepted Xth $X X X X X X X X X 20 X X$ \\ DOI: $10.1039 / b 000000 x$
}

The azulene-substituted butadiynes have been prepared by $\mathrm{Cu}$-mediated cross- and homo-coupling reaction. The azulene-substituted butadiynes reacted with tetracyanoethylene in a formal $[2+2]$ cycloaddition reaction to afford the corresponding 1,1,4,4-tetracyanobutadiene chromophores, 10 respectively, in excellent yields. Further [2+2] cycloaddition with TTF and TCNE gave novel donoracceptor chromophores and novel azulene-substituted 6,6-dicyanofulvene derivative.

\section{Introduction}

Tetrathiafulvalene (TTF) is well known as a powerful electron donor to form CT complexes with a variety of electron-deficient 15 organic compounds because of the formation of stable aromatic 1,3-dithiole rings by one- or two-electron oxidation. Thus, TTF and its derivatives have attracted much attention as conductive components of molecular conductors. ${ }^{1}$

At the first time, Hopf et al. have reported the $[2+2]$ 20 cycloaddition reaction of TTF, a strong electron donor, with electron-deficient acetylenes with dicyanoethylene substituent to afford 1,2-bis(1,3-dithiol-2-ylidene)ethane derivatives with dicyanoethylene substituent. ${ }^{2}$ As an extension of this study, Diederich et al. have reported the sequential [2+2] cycloaddition 25 reaction of tetracycnoethylene (TCNE) and TTF with dialkylamino- (DAA-) substituted electron-rich butadiynes yielding multivalent charge-transfer (CT) chromophores, tetracyanobutadiene (TCBD)/1,2-bis(1,3-dithiol-2-ylidene)ethane derivatives, that are capable of taking up an exceptional number 30 of electrons under electrochemical conditions. ${ }^{3}$

Azulene $\left(\mathrm{C}_{10} \mathrm{H}_{8}\right)$ has attracted the interest of many research groups owing to its unusual properties as well as its beautiful blue color. ${ }^{4}$ Recently, we have also reported the reaction of poly(1azulenylethynyl)benzene and thiophene derivatives with TCNE 35 and TCNQ to give the corresponding intramolecular CT chromophores, which exhibit a multistep reduction wave on cyclic voltammetry (CV), in excellent yields. ${ }^{5}$

Previously, Hafner et al. reported the preparation of 1azulenylbutadiynes utilizing a $\mathrm{Cu}$-meditated oxidative coupling 40 under Eglinton conditions. ${ }^{6}$ Although 1-azulenylbutadiynes are one of promising building blocks for the construction of novel CT chromophores, reactivity of their derivatives is not energetically investigated so far. As similar to the DAA-substituent, 1-position of azulene ring possesses strong electron-donating properties with 45 high reactivity toward electrophilic substitution reactions. Thus, butadiyne derivatives substituted by 1-azulenyl moiety should be expected to afford a new series of donor-acceptor chromophores by the sequential $[2+2]$ cycloaddition reactions with TCNE and TTF. Furthermore, azulene-substituted donor-acceptor 50 chromophores may exhibit multistage amphoteric redox behaviour with redox reaction of the azulene core.

Herein, we report the synthesis of novel azulene-substituted donor-acceptor chromophores by the sequential $[2+2]$ cycloaddition of 1-azulenylbutadiynes with TCNE and TTF, as 55 well as spectroscopic and electrochemical properties of the novel donor-acceptor chromophores clarified by UV/Vis spectrometry and electrochemical analysis.

\section{Results and discussion}

Synthesis

${ }_{60}$ Preparation of azulene-substituted butadiene derivatives, i.e., methyl 7-isopropyl-3-(4-phenylbuta-1,3-diynyl)azulene-1carboxylate (2), 1,4-bis(7-isopropyl-1-methoxycarbonylazulen-3yl)buta-1,3-diyne (3), and methyl 7-isopropyl-3-(4trimethylsilylbuta-1,3-diynyl)azulene-1-carboxylate (4) was ${ }_{65}$ investigated by $\mathrm{Cu}$-mediated $\mathrm{Hay}^{7}$ cross- and Glaser ${ }^{8}$ homocoupling conditions, respectively (Scheme 1). The cross-coupling reaction of methyl 7-isopropyl-3-ethynylazulene-1-carboxylate $(\mathbf{1})^{5}$ with 5 equiv. of ethynylbenzene, using $\mathrm{CuI} /$ tetramethylethylenediamine (TMEDA) as the catalysts, and 70 subsequent chromatographic purification on silica gel afforded the desired 2 in 74\% yield, along with the homo-coupling product $\mathbf{3}$ in $20 \%$ yield. Compound $\mathbf{3}$ was also obtained in $91 \%$ yield as a sole product, by the Glaser homo-coupling reaction of $\mathbf{1}$ under the similar reaction conditions. Similar with the synthesis of $\mathbf{2}$, 75 butadiyne 4 was obtained by the reaction of 1 with 5 equiv. trimethylsilylacetylene in $76 \%$ yield, along with 3 in $17 \%$ yield. These butadiyne derivatives $\mathbf{2}, \mathbf{3}$ and $\mathbf{4}$ possess fair solubility in 
chloroform, dichloromethane, and so on. Moreover, they are stable and showing no decomposition, even after several weeks at room temperature. Thus, these butadiyne derivatives could be utilized in further transformations for the synthesis of novel 5 donor-acceptor chromophores owing to their considerable stability and solubility.

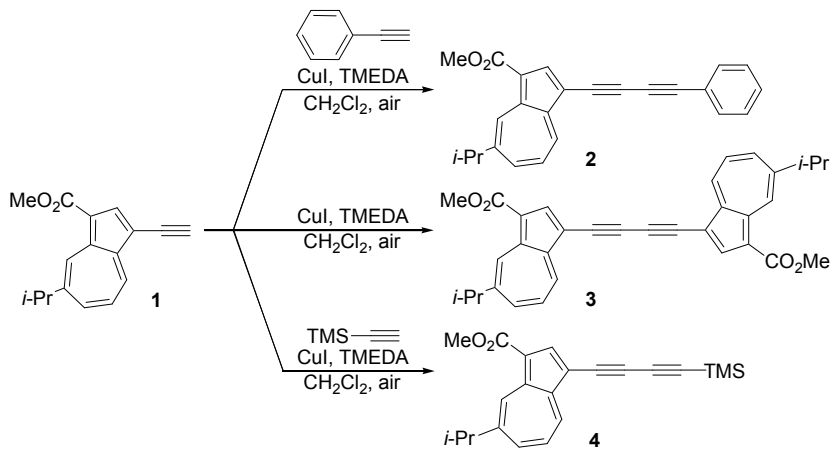

Scheme 1 Synthesis of 1-azulenylbutadiynes 2, 3 and 4.

The sequential [2+2] cycloaddition reaction of $\mathbf{2}$ and $\mathbf{3}$ with 10 TCNE and TTF was examined for the construction of novel donor-acceptor chromophores. Thus, the reaction of $\mathbf{2}$ with TCNE was examined in ethyl acetate at room temperature to yield 5 in $95 \%$ yield. $^{3,5,9}$ Subsequent $[2+2]$ cycloaddition reaction of $\mathbf{5}$ with excess TCNE in the remaining ethynyl moiety,

15 contiguous to the phenyl group, did not proceed even under the refluxing conditions in DMF. These results indicate the low reactivity of the $\mathrm{C} \equiv \mathrm{C}$ triple bond attached to the highly electronwithdrawing TCBD moiety. The synthesis of the TCNE/TTF double adduct 6 was achieved in $92 \%$ yield by the $[2+2]$ 20 cycloaddition reaction of $\mathbf{5}$ with TTF (Scheme 2). The one-pot cascade reaction of $\mathbf{2}$ with TCNE and TTF also gave $\mathbf{6}$ in $70 \%$ yield, which corresponds to $84 \%$ yield in each step. However, the cascade reaction requires a tedious separation process.
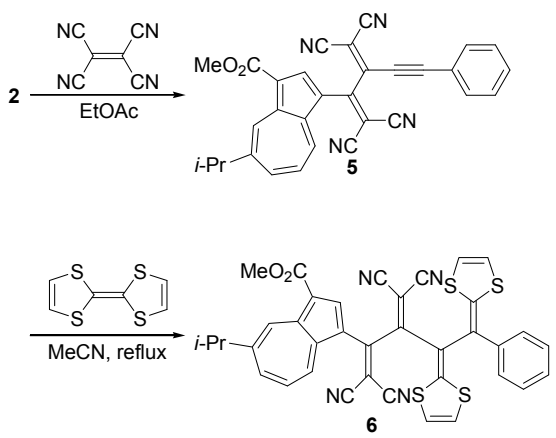

25 Scheme 2

Likewise, the reaction of butadiyne $\mathbf{3}$ with TCNE at room temperature afforded TCBD 7 in $97 \%$ yield. Although the resulting 7 was treated with TTF, the corresponding TCNE/TTF 30 double-adduct could not be obtained, but resulting into the recovery of the TCBD 7. Meanwhile, subsequent $[2+2]$ cycloaddition of 7 with TCNE was observed under the refluxing conditions in 1,1,2,2-tetrachloroethane to afford the double TCNE-adduct 8 in $71 \%$ yield, along with novel 6,6-
${ }_{35}$ dicyanofulvene derivative 9 in $22 \%$ yield (Scheme 3 ).
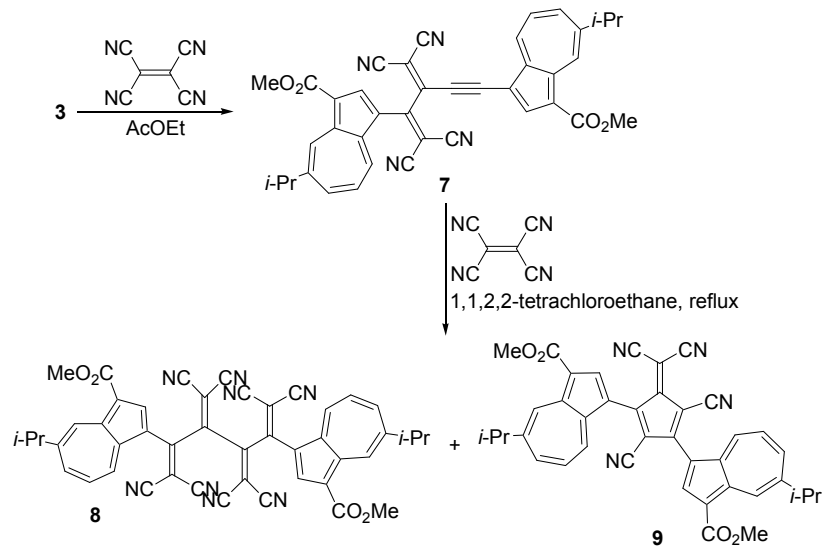

Scheme 3

When the compounds 7 and 8 were refluxed in 1,1,2,240 tetrachloroethane without TCNE, 6,6-dicyanofulvene 9 could not be obtained, but resulting into the recovery of the starting compounds 7 and 8. Thus, TCNE has important role for the formation of 6,6-dicyanofulvene derivative 9. The presumed reaction mechanism for the formation of $\mathbf{8}$ and $\mathbf{9}$ is illustrated in ${ }_{45}$ Scheme 4. This reaction should involve two reaction pathways to afford 8 and 9. Initially, TCNE exhibits coordination to 7 with electron-rich acetylene moiety attached to 1-azulenyl group. In one pathway, the TCNE molecule undergoes $[2+2]$ cycloaddition with the acetylene moiety of 7 to afford the ${ }_{50}$ cyclobutene intermediate. Subsequent ring-opening reaction of the cyclobutene derivative gives the thermodynamically stable TCBD derivative $\mathbf{8}^{10}$ As another mechanism, the dicyanomethylidene group attached to the azulene ring in 7 , which has certain electronegativity by the conjugation with 155 azulenyl group, attacks to intramolecular acetylene moiety with a decreased LUMO-level by the TCNE coordination, to form a five-membered ring of 9'. In the generated zwitter ionic species 9', the migration of a cyano group results into the formation of 6,6-dicyanofulvene derivative 9. ${ }^{11}$ Recently, Diederich et al. have 60 reported the first synthesis of donor-substituted 6,6dicyanofulvene derivative with interesting optoelectronic properties. ${ }^{12}$ In the view point of azulene chemistry, compound 9 is the first example of 6,6'-dicyanofulvene derivative substituted by azulene ring. 


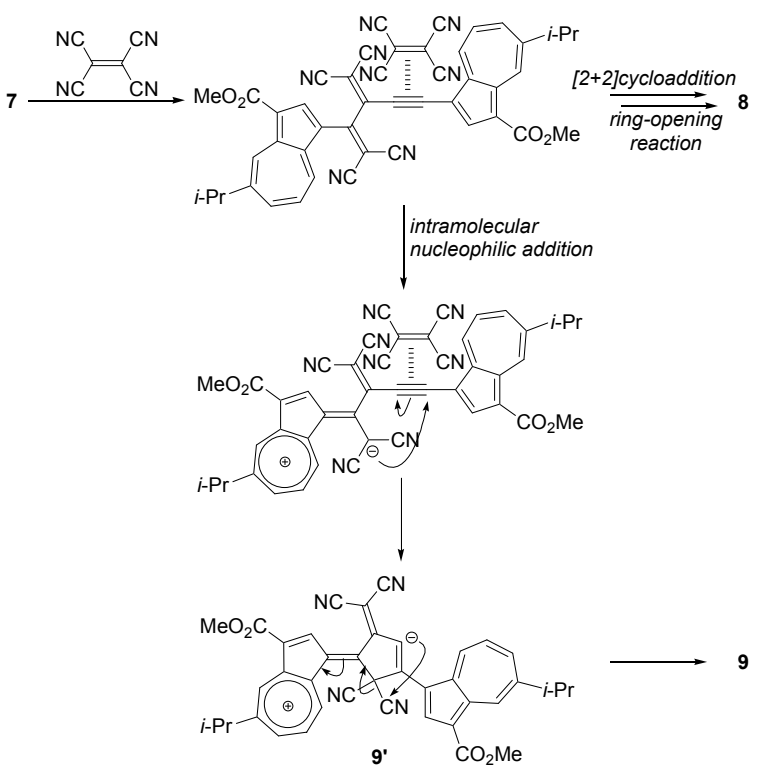

Scheme 4 Presumed reaction mechanism for the formation of $\mathbf{8}$ and $\mathbf{9}$.

Compounds 11 was prepared by the Pd-catalyzed alkynylation of 1,4-diiodobenzene with butadiyne 10, which was prepared by 5 the desilylation of $\mathbf{4}$, under Sonogashira-Hagihara conditions (Scheme 5). A solution of $\mathbf{4}$ in methanol was treated with a potassium carbonate solution to generate the corresponding butadiyne 10. The green solid 10 decomposed at room temperature, but has certain stability in solution to be 10 employed for further transformation. The cross-coupling reaction of 10 with 1,4-diiodobenzene using $\mathrm{Pd}\left(\mathrm{PPh}_{3}\right)_{4}$ as a catalyst, and subsequent chromatographic purification of the reaction mixture on silica gel, afforded the desired $\mathbf{1 1}$ in $87 \%$ yield. As similar to the results on the butadiynes $\mathbf{2}$ and $\mathbf{3}$, the 15 reaction of 11 with TCNE afforded bis-adduct 12 in $95 \%$ yield. To the synthesis of the TCNE/TTF double adduct, the $[2+2]$ cycloaddition reaction of $\mathbf{1 2}$ with TTF was also examined under the similar conditions for the preparation of $\mathbf{6}$. However, in contrast to the results on the reaction of $\mathbf{6}$, the reaction of $\mathbf{1 2}$ with

${ }_{20}$ TTF formed an insoluble complex mixture. It should be attributed to instability of the compound under the reaction conditions.
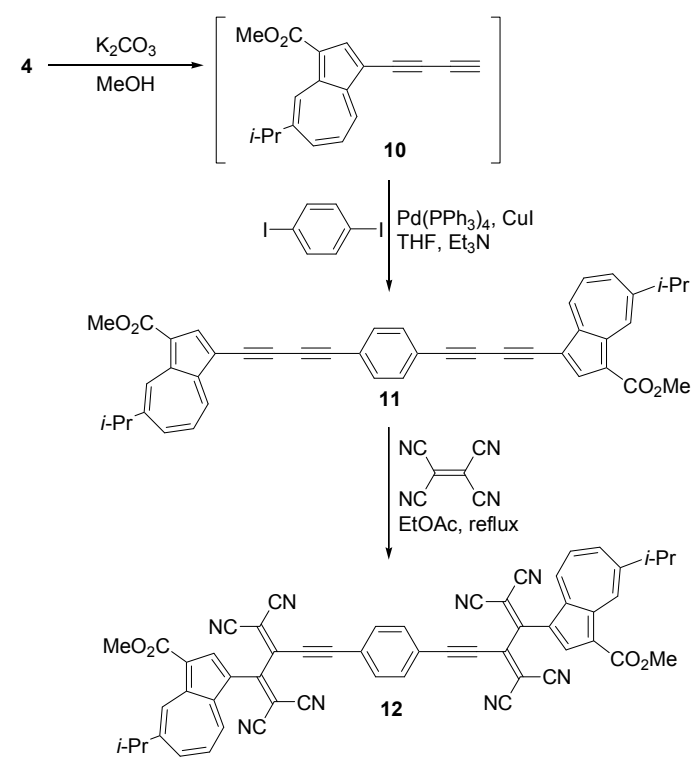

Scheme 5

\section{${ }_{25}$ Spectroscopic Properties}

The structure of these novel compounds 2-12 was confirmed by spectral data including ${ }^{1} \mathrm{H},{ }^{13} \mathrm{C}$ NMR, HMQC, HMBC and NOE experiments, except for $\mathbf{1 0}$. The absorption maxima $\left(\lambda_{\max }\right)$ and their coefficients $(\log \varepsilon)$ of the new compounds 5-9 and $\mathbf{1 2}$ are 30 summarized in Table 1.

Table 1 Absorption maxima [nm] and their coefficients (log $\varepsilon$ ) of DCNQ chromophores 10-18 in dichloromethane and in $10 \% \mathrm{CH}_{2} \mathrm{Cl}_{2} /$ hexane.

\begin{tabular}{lll}
\hline Sample & $\lambda_{\max }(\log \varepsilon)$ in $\mathrm{CH}_{2} \mathrm{Cl}_{2}$ & $\lambda_{\max }(\log \varepsilon)$ in hexane \\
\hline $\mathbf{5}$ & $388(4.47), 530(3.93)$ & $513(3.87)^{a}$ \\
$\mathbf{6}$ & $471(4.52)$ & $463(4.48)^{a}$ \\
$\mathbf{7}$ & $394(4.33), 545(4.52)$ & $392(4.29), 515(4.49)^{a}$ \\
$\mathbf{8}$ & $450(4.40), 510 \operatorname{sh}(4.19)$ & $419(4.25), 438(4.24), 488$ \\
& & $\operatorname{sh}(4.17)^{a}$ \\
$\mathbf{9}$ & $542 \operatorname{sh}(4.03), 583(4.11)$, & $530 \operatorname{sh}(4.04), 570(4.11)$, \\
& $808(3.64)$ & $755(3.50)^{a}$ \\
$\mathbf{1 2}$ & $443(4.46), 544 \operatorname{sh}(4.11)$ & $438(4.46), 544 \mathrm{sh}(4.04)^{b}$
\end{tabular}

${ }^{a}$ Dichloromethane (10\%) was included to keep the solubility of these compounds. ${ }^{b}$ Dichloromethane $(20 \%)$ was included to keep the solubility 35 of these compounds.

The UV/Vis spectra of butadiynes $\mathbf{2 , 3 , 4}$ and $\mathbf{1 1}$ showed weak characteristic absorption bands arising from the azulene moiety in the visible region. As expected from their structures, TCBD 40 derivatives, TCNE/TTF double-adduct 6 and 6,6-dicyanofulvene 9 showed relatively strong CT absorption bands in the visible region (Figures 1-3). The spectrum of 5 in dichloromethane displayed a characteristic CT absorption band at $\lambda_{\max }=530 \mathrm{~nm}$ $(\log \varepsilon=3.93)$. The UV/Vis spectrum of 6 exhibited strong and ${ }_{45}$ broad absorption band at $\lambda_{\max }=471 \mathrm{~nm}$ in dichloromethane, which might be reflected to the overlapping of the CT absorption bands between two-donor moieties [i.e., azulene and 1,2-bis(1,3dithiol-2-ylidene)ethane] and TCBD-acceptor unit (Figure 1). 


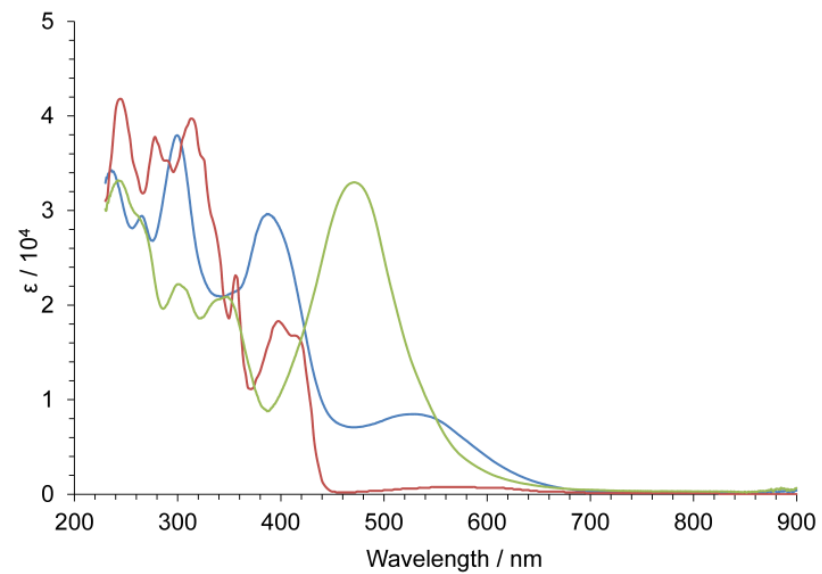

Fig. 1 UV/Vis spectra of 2 (blue line), 5 (red line) and $\mathbf{6}$ (green line) in dichloromethane.

Compound 7 exhibited two CT absorption bands at $\lambda_{\max }=394$ $5 \mathrm{~nm}$ (weak) and $\lambda_{\max }=545 \mathrm{~nm}$ (strong) in dichloromethane (Figure 2). The longest absorption of 7 displayed a bathochromic shift by $15 \mathrm{~nm}$ compared with that of $\mathbf{5}\left(\lambda_{\max }=530 \mathrm{~nm}\right)$. These results indicate that the $\pi$-conjugation is efficiently expanded by the 1-azulenyl group rather than phenyl group substituted. Broad ${ }_{10} \mathrm{CT}$ absorption centered at $\lambda_{\max }=450 \mathrm{~nm}$ was also observed in $\mathbf{8}$, of which the band extended beyond $\lambda_{\max }=800 \mathrm{~nm}$ (Figure 2). The UV/Vis spectrum of 9 displayed two-broad absorption centered at $\lambda_{\max }=583 \mathrm{~nm}$ and $\lambda_{\max }=808 \mathrm{~nm}$ in dichloromethane. When the solvent was changed to $10 \%$ dichloromethane in

15 hexane that possess much lower polarity, these bands showed apparent blue-shift to $\lambda_{\max }=572 \mathrm{~nm}$ and $753 \mathrm{~nm}$, respectively. These results suggest the intramolecular CT characters of these absorption bands (Figure 3). ${ }^{13}$ The bis-TCNE adduct 12 exhibited a strong and broad CT absorption band at $443 \mathrm{~nm}$ 20 and $544(\mathrm{sh}) \mathrm{nm}$ in dichloromethane.

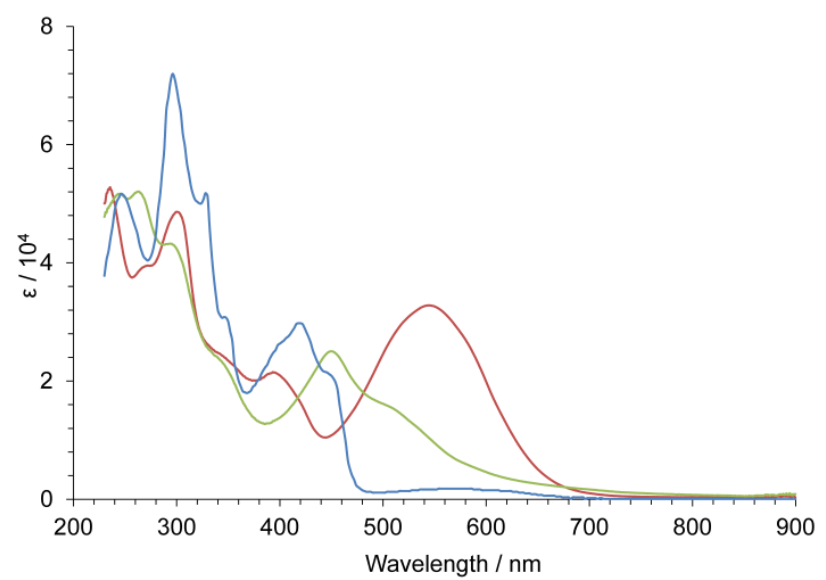

Fig. 2 UV/Vis spectra of 3 (blue line), 7 (red line) and $\mathbf{8}$ (green line) in dichloromethane.

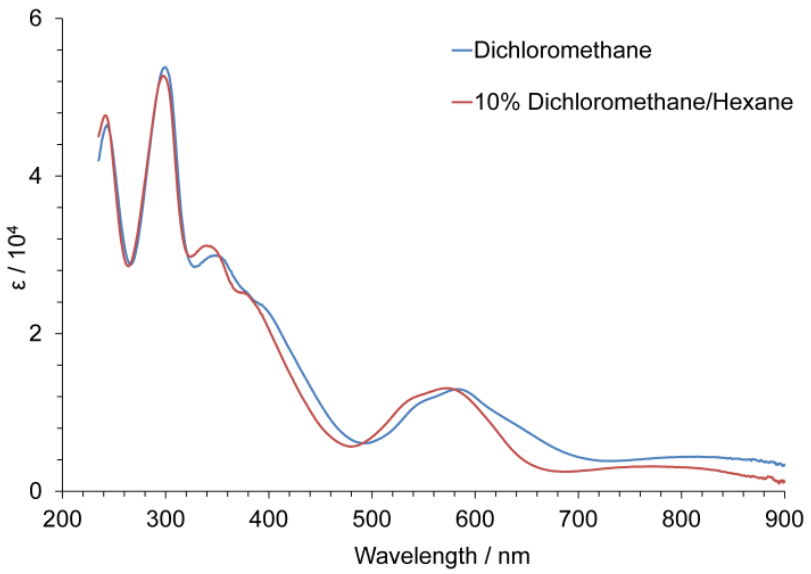

${ }_{25}$ Fig. 3 Solvent dependence for UV/Vis spectra of 9 in dichloromethane (blue line) and 10\% dichloromethane/hexane (red line).

The time dependence density functional theory (TD-DFT) calculation was performed for 9', in which the isopropyl group was replaced with $\mathrm{H}$ group, in order to clarify an origin for broad 30 absorption of 9. ${ }^{14}$ The frontier Kohn-Sham orbitals of 9"' are shown in Figure 4. The broad CT-absorption beyond to nearinfrared region of 9" originated from the HOMO located on azulene-ring to the LUMO that was mainly located on the 6,6dicyanofulvene moiety. The broad absorption of 9 centered at ${ }_{35} \lambda_{\max }=583 \mathrm{~nm}$ is confirmed that the absorption band arisen from the overlapping of some transition as shown in Table 2 .

HOMO

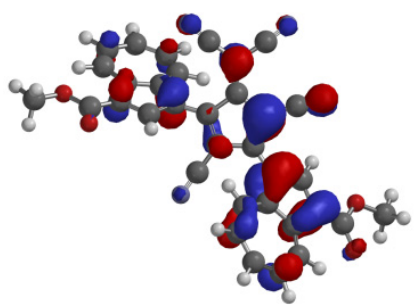

HOMO-1

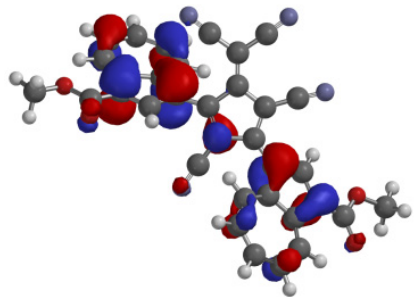

HOMO-2

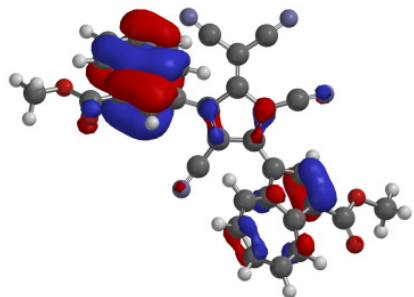

Fig. 4 Frontier Kohn-Sham orbitals of 9" at the B3LYP/6-31G** level.
$\mathrm{LUMO}+2$

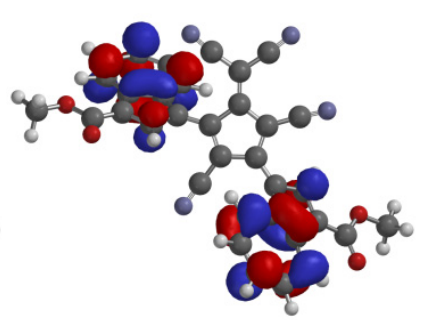

LUMO

$\mathrm{LUMO}+1$

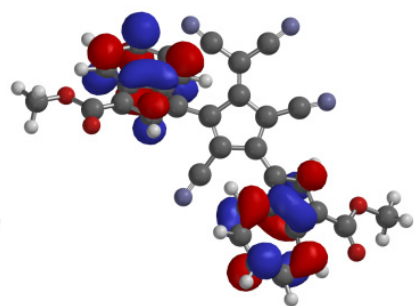

(1) 
Table 2 Electronic transitions for 9" derived from the computed values based on B3LYP/6-31G ${ }^{* *}$ method and experimental values from 9 .

\begin{tabular}{|c|c|c|c|}
\hline \multirow{2}{*}{$\begin{array}{l}\text { Experimental } \\
\lambda_{\max }(\log \varepsilon)\end{array}$} & \multicolumn{2}{|c|}{ Computed Value } & \multirow[b]{2}{*}{$\begin{array}{l}\text { Composition of band }{ }^{a, b} / \mathrm{CI} \\
\text { coefficients }^{c}\end{array}$} \\
\hline & $\lambda_{\max }$ & Strength & \\
\hline $808(3.64)$ & 815 & 0.0853 & $\mathrm{H} \rightarrow \mathrm{L} / 0.94$ \\
\hline $583(4.11)$ & 611 & 0.5618 & $\begin{array}{l}\mathrm{H}-2 \rightarrow \mathrm{L} / 0.27 \\
\mathrm{H}-1 \rightarrow \mathrm{L} / 0.89\end{array}$ \\
\hline $542 \operatorname{sh}(4.03)$ & $\begin{array}{l}533 \\
522\end{array}$ & $\begin{array}{l}0.0062 \\
0.0067\end{array}$ & $\begin{array}{l}\mathrm{H} \rightarrow \mathrm{L}+2 / 0.62 \\
\mathrm{H}-1 \rightarrow \mathrm{L}+1 / 0.40 \\
\mathrm{H} \rightarrow \mathrm{L}+1 / 0.55 \\
\mathrm{H} \rightarrow \mathrm{L}+2 / 0.59\end{array}$ \\
\hline
\end{tabular}

\section{${ }_{5}$ Electrochemistry}

To clarify the electrochemical properties, the redox behavior of 5-9 and 12 was examined by $\mathrm{CV}$ and differential pulse voltammetry (DPV). The redox potentials (in volts vs $\mathrm{Ag} / \mathrm{AgNO}_{3}$ ) of 5-9 and $\mathbf{1 2}$ are summarized in Table 3. The cyclic 10 voltammograms of 6, 8 and $\mathbf{1 2}$ are shown in Figures 5, 6 and 7, respectively.

Table 3 Redox potentials ${ }^{[a]}$ of the compounds $5-\mathbf{9}$ and $\mathbf{1 2}$.

\begin{tabular}{|c|c|c|c|c|c|c|}
\hline Sample & Method & $E_{1}{ }^{\text {ox }}$ & $E_{1}{ }^{\text {red }}$ & $E_{2}{ }^{\text {red }}$ & $E_{3}{ }^{\text {red }}$ & $E_{4}{ }^{\text {red }}$ \\
\hline 5 & $\begin{array}{l}\mathrm{CV} \\
(\mathrm{DPV})\end{array}$ & $(+1.87)$ & $\begin{array}{l}-0.39 \\
(-0.37)\end{array}$ & $\begin{array}{l}-0.87 \\
(-0.85)\end{array}$ & & \\
\hline 6 & $\begin{array}{l}\mathrm{CV} \\
\text { (DPV) }\end{array}$ & $\begin{array}{l}+0.57 \\
(+0.56)\end{array}$ & $\begin{array}{l}-0.80 \\
(-0.78)\end{array}$ & $\begin{array}{l}-1.08 \\
(-1.06)\end{array}$ & & \\
\hline 7 & $\begin{array}{l}\mathrm{CV} \\
\text { (DPV) }\end{array}$ & $(+1.21)$ & $\begin{array}{l}-0.49 \\
(-0.47)\end{array}$ & $\begin{array}{l}-0.90 \\
(-0.88)\end{array}$ & $\begin{array}{l}-1.76 \\
(-1.74)\end{array}$ & \\
\hline 8 & $\begin{array}{l}\mathrm{CV} \\
\text { (DPV) }\end{array}$ & $(+1.40)$ & $\begin{array}{l}+0.23 \\
(+0.21)\end{array}$ & $\begin{array}{l}-0.37 \\
(-0.35)\end{array}$ & $\begin{array}{l}-1.33 \\
(-1.31)\end{array}$ & $(-1.66)$ \\
\hline 9 & $\begin{array}{l}\mathrm{CV} \\
\text { (DPV) }\end{array}$ & $(+0.98)$ & $\begin{array}{l}-0.32 \\
(-0.30)\end{array}$ & $\begin{array}{l}-0.59 \\
(-0.57)\end{array}$ & $(-1.75)$ & \\
\hline 12 & $\begin{array}{l}\mathrm{CV} \\
\text { (DPV) }\end{array}$ & $(+1.35)$ & $\begin{array}{l}-0.44 \\
(-0.42)\end{array}$ & $\begin{array}{l}-0.62 \\
(-0.60)\end{array}$ & $\begin{array}{l}-0.99 \\
(-0.97)\end{array}$ & $\begin{array}{l}-1.08 \\
(-1.06)^{[b]}\end{array}$ \\
\hline
\end{tabular}

${ }^{a}$ Redox potentials were measured by $\mathrm{CV}$ and $\mathrm{DPV}\left[\mathrm{V}\right.$ vs $\mathrm{Ag} / \mathrm{AgNO}_{3}, 1$ $\mathrm{mM}$ in benzonitrile containing $\mathrm{Et}_{4} \mathrm{NClO}_{4}(0.1 \mathrm{M})$, Pt electrode (internal 15 diameter: $1.6 \mathrm{~mm})$, scan rate $=100 \mathrm{mVs}^{-1}$, and $\left.\mathrm{Fc} / \mathrm{Fc}^{+}=+0.15 \mathrm{~V}\right]$. In the case of reversible waves, redox potentials measured by $\mathrm{CV}$ are presented. The peak potentials measured by DPV are shown in parentheses.

${ }^{b}$ The $E_{5}{ }^{\text {red }}$ and $E_{6}{ }^{\text {red }}$ were observed at $-1.88 \mathrm{~V}$ and $-1.96 \mathrm{~V}$, respectively.

20 All novel donor-acceptor chromophores 5-9 and 12 showed reversible reduction waves on $\mathrm{CV}$. The TCBD derivative $\mathbf{5}$ exhibited a reversible two-step reduction wave, of which potentials were identified at $-0.39 \mathrm{~V}$ and $-0.87 \mathrm{~V}$ by CV. These results should be attributable to the generation of dianionic 25 species owing to electron acceptance by the TCBD moiety, as illustrated in Scheme 6.

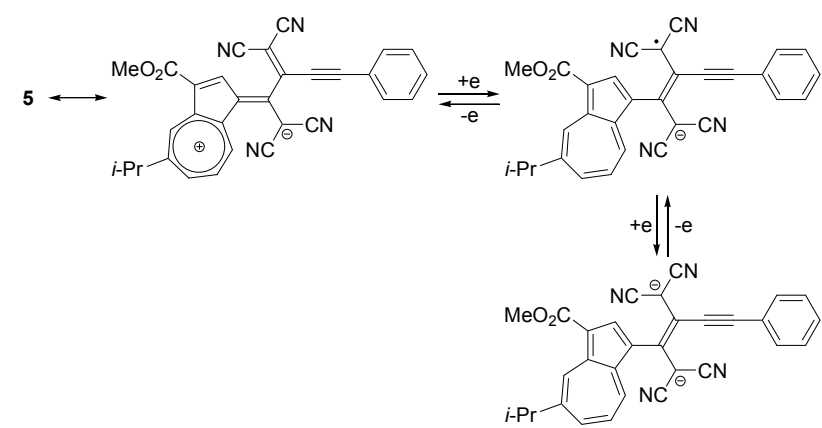

Scheme 6 Presumed electrochemical behavior of 5.

30 In the case of the electrochemical analysis of $\mathbf{6}$, a reversible one-stage two-electron oxidation wave $(+0.57 \mathrm{~V})$ and two-step reduction wave $(-0.80 \mathrm{~V}$ and $-1.08 \mathrm{~V})$ was observed on $\mathrm{CV}$, owing to the redox activities of TCBD and 1,2-bis(1,3-dithiol-2ylidene)ethane units (Figure 5). The first reduction potential of 6 $35(-0.80 \mathrm{~V})$ was much more negative than that of $5(-0.39 \mathrm{~V})$. These results indicate that the 1,2-bis(1,3-dithiol-2ylidene)ethane substituent on $\mathbf{6}$ leads to an increase in the LUMO-level of the molecule, due to the strong electron-donating nature of the 1,2-bis(1,3-dithiol-2-ylidene)ethane moiety.

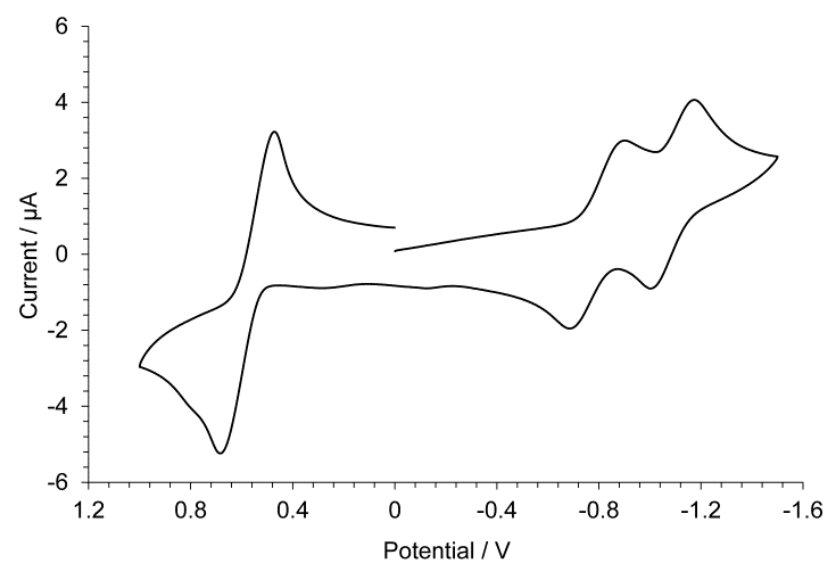

Fig. 5 Cyclic voltammogram of $6(1 \mathrm{mM})$ in benzonitrile containing $\mathrm{Et}_{4} \mathrm{NClO}_{4}(0.1 \mathrm{M})$ as a supporting electrolyte; scan rate $=100 \mathrm{mVs}^{-1}$.

The electrochemical reduction of 7 showed a reversible threestage wave on $\mathrm{CV}(-0.49 \mathrm{~V},-0.90 \mathrm{~V}$ and $-1.76 \mathrm{~V})$ by the 45 formation up to a trianionic species, which may include the reduction of an azulene ring. The electrochemical reduction of $\mathbf{8}$ exhibited a reversible three-step reduction wave, whose potentials were identified at $+0.21 \mathrm{~V},-0.35 \mathrm{~V}$ and $-1.31 \mathrm{~V}$ by DPV, in which the second reduction wave should be concluded to be a 50 two-electron transfer in one step to form a tetraanionic species (Figure 6). The first reduction of $\mathbf{8}(+0.23 \mathrm{~V})$ showed rather less negativity, compared with those of $5(-0.39 \mathrm{~V})$ and $7(-0.49 \mathrm{~V})$. Furthermore, the first reduction potential of $\mathbf{8}$ exhibited the least negative value, compared with those of TCBD and ${ }_{55}$ dicyanoquinodimethane (DCNQ) derivatives ever reported. ${ }^{15}$ These results indicate that combined two TCBD units in $\mathbf{8}$ fairly reduce the LUMO-level resulted into the increase of the $\pi$ accepting property. 
A reversible two-stage wave was also observed in 9 on $\mathrm{CV}$ $(-0.32 \mathrm{~V}$ and $-0.59 \mathrm{~V})$, owing to the formation of a dianionic species. The electrochemical reduction of $\mathbf{1 2}$ exhibited a reversible four-step reduction wave, the potentials of which were 5 identified at $-0.42,-0.60,-0.97$ and $-1.06 \mathrm{~V}$ by DPV, which were attributed to the formation up to a tetraanionic species due to the reduction of the two TCBD moieties (Figure 7).

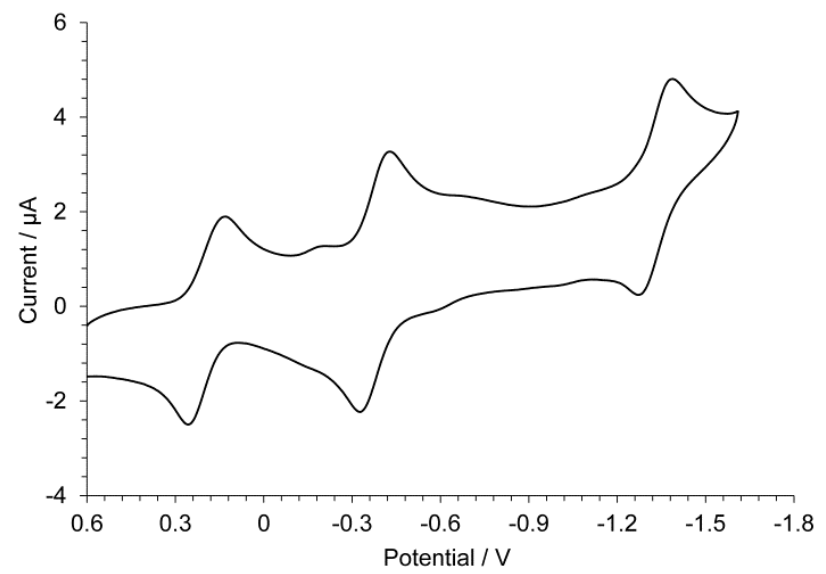

Fig. 6 Cyclic voltammogram of $8(1 \mathrm{mM})$ in benzonitrile containing $10 \mathrm{Et}_{4} \mathrm{NClO}_{4}(0.1 \mathrm{M})$ as a supporting electrolyte; scan rate $=100 \mathrm{mVs}^{-1}$.

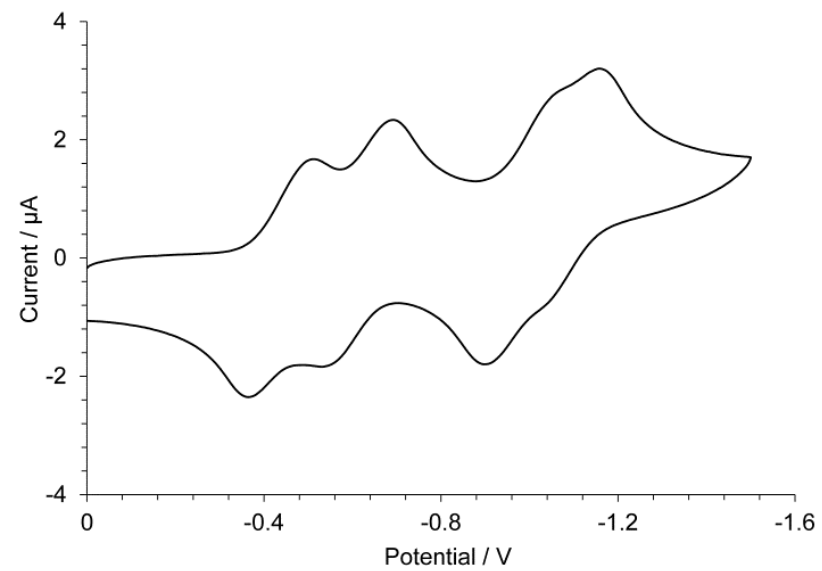

Fig. 7 Cyclic voltammogram of $\mathbf{1 2}(1 \mathrm{mM})$ in benzonitrile containing $\mathrm{Et}_{4} \mathrm{NClO}_{4}(0.1 \mathrm{M})$ as a supporting electrolyte; scan rate $=100 \mathrm{mVs}^{-1}$.

\section{Conclusions}

15 In conclusion, azulene-substituted butadiynes $\mathbf{2}, \mathbf{3}$ and $\mathbf{4}$ were prepared by Hay and Glaser reactions, respectively. A series of azulene-substituted TCBD chromophores possessing the acetylene moiety $\mathbf{5}$ and 7 were synthesized by the $[2+2]$ cycloaddition reaction of $\mathbf{2}$ and $\mathbf{3}$, respectively, with TCNE. The $20[2+2]$ cycloaddition of $\mathbf{5}$ with TTF gave novel donor-acceptor chromophore 6 . The reaction of 7 with TCNE gave the product 8 with two TCBD moieties and 6,6-dicyanofulvene derivative 9. Compounds 11 was prepared by the Pd-catalyzed alkynylation of 1,4-diiodobenzene with butadiyne 10, which was prepared by the 25 desilylation of 4, under Sonogashira-Hagihara conditions. The synthesis of the TCNE/TTF double adduct of $\mathbf{1 0}$ was also examined, but the [2+2] cycloaddition reaction of $\mathbf{1 2}$ with TTF did not afford the presumed double adduct. An analysis by CV and DPV showed that compound $\mathbf{6}$ exhibited attractive 30 amphoteric redox properties, owing to the electrochemical oxidation of 1,2-bis(1,3-dithiol-2-ylidene)ethane and reduction of TCBD moieties. It is noteworthy that the first reduction potential of $\mathbf{8}$ with two TCBD moieties exhibited the least negative value, compared with those of TCBD and DCNQ derivatives ever

35 reported. Construction of reversible multistage redox systems based on the donor-acceptor system is currently examined in our laboratory.

\section{Acknowledgements}

This work was partially supported by a Grant-in-Aid for Research 40 Activity Start-up (Grant 22850007 to T.S.) from the Ministry of Education, Culture, Sports, Science, and Technology, Japan.

\section{Notes and references}

${ }^{a}$ Department of Chemistry, Faculty School of Science, Shinshu University, Matsumoto 390-8621, Japan. Fax: 81263 2476; Tel: 81263 2476; E45 mail: tshoji@shinshu-u.ac.jp

${ }^{b}$ Graduate School of Science and Technology, Hirosaki University, Hirosaki 036-8561, Japan.

${ }^{c}$ Department of Chemistry and Biology, Graduate School of Science and Engineering, Ehime University, Matsuyama 790-8577, Japan.

${ }_{50}{ }^{d}$ Department of Chemistry, Graduate School of Science, Tohoku University, Sendai 980-8578, Japan.

$\uparrow$ Electronic Supplementary Information (ESI) available: The experimental, UV/Vis spectra and cyclic voltammograms of reported compounds. See DOI: 10.1039/b000000x/

551 Special Issue on Molecular Conductors: Chem. Rev. 2004, 104, 4887-5782, edited by P. Batail.

2 H. Hopf, M. Kreutzer, M. P. G. Jones, Angew. Chem. Int. Ed. 1991, 30, 1127-1128.

3 (a) M. Kivala, C. Boudon, J.-P. Gisselbrecht, P. Seiler, M. Gross, F. 60 Diederich, Angew. Chem. Int. Ed. 2007, 46, 6357-6360; (b) B. B Frank, M. Kivala, B. C. Blanco, B. Breiten, Schweizer, P. R. Laporta, I. Biaggio, E. Jahnke, R. R. Tykwinski, C. Boudon, J.-P Gisselbrecht, F. Diederich, Eur. J. Org. Chem. 2010, 2487-2503.

4 K.-P. Zeller, Azulene in Methoden der Organischen Chemie

65 (Houben-Weyl) (Ed.: Kropf, H.), 4th ed., Thieme, Stuttgart, Germany, 1985, vol. V, part 2c, pp. 127-418.

5 (a) T. Shoji, S. Ito, K. Toyota, M. Yasunami, N. Morita, Chem. Eur J. 2008, 14, 8398-8408; (b) T. Shoji, S. Ito, K. Toyota, T. Iwamoto, M. Yasunami, N. Morita, Eur. J. Org. Chem. 2009, 4316-4324; (c)

70 T. Shoji, M. Maruyama, S. Ito, N. Morita, Bull. Chem. Soc. Jpn. $2012, \mathbf{8 5}, 761-773$.

6 (a) A. H. M. Elwahy, K. Hafner, Tetrahedron Lett. 2000, 41, 2859 2862; (b) K. H. H. Fabian, A. H. M. Elwahy, K. Hafner, Eur. J. Org. Chem. 2006, 791-802; (c) A. H. M. Elwahy, K. Hafner, Eur. J. Org. Chem. 2006, 3910-3916.

7 A. S. Hay, J. Org. Chem. 1962, 27, 3320-3321.

8 (a) C. Glaser, Chem. Ber. 1869, 2, 422-424; (b) P. Siemsen, R. C. Livingstone, F. Diederich, Angew. Chem. Int. Ed. 2000, 39, 26322657.

${ }_{80} 9$ (a) J. Xu, X. Liu, J. Lv, M. Zhu, C. Huang, W. Zhou, X. Yin, H. Liu, Y. Li, J. Ye, Langmuir, 2008, 24, 4231-4237; (b) W. Zhou, J. $\mathrm{Xu}$, H. Zheng, H. Liu, Y. Li, D. Zhu, J. Org. Chem., 2008, 73, 7702-7709; (c) W. Zhou, J. Xu, H. Zheng, X. Yin, Z. Zuo, H. Liu, Y. Li, Adv. Funct. Mater. 2009, 19, 141-149; (d) H. Liu, J. Xu, Y. 85 Li, Y. Li, Acc. Chem. Res., 2010, 43 ,1496-1508; (c) S. Chen, Y. Li, C. Liu, W. Yang, Y. Li, Eur. J. Org. Chem., 2011, 6445-6451. 
10 A detailed reaction mechanism was recently reported: Y-.L. Wu, P. D. Jarowski, W. B. Schweizer, F. Diederich, Chem. Eur. J. 2010, 16, 202-211.

11 Intramolecular migration of cyano group was recently reported: $\mathrm{M}$.

5 Yamada, W. B. Schweizer, F. Schoenebeck, F. Diederich, Chem. Commun., 2010, 46, 5334-5336.

12 G. Jayamurugan, J.-P. Gisselbrecht, C. Boudon, F. Schoenebeck, W. B. Schweizer, B. Berneta, F. Diederich, Chem. Commun. 2011, 47, $4520-4522$.

1013 (a) P. Suppan, N. Ghoneim, Solvatochromism, Royal Society of Chemistry, Cambridge, 1997; (b) P. Suppan, J. Photochem. Photobiol. A 1990, 50, 293-330; (c) C. Reichardt, Solvent and Solvent Effects in Organic Chemistry, Wiley-VCH, New York, 2004.

1514 The B3LYP/6-31G** time-dependence density functional calculation was performed with Spartan'10, Wavefunction, Irvine, CA.

15 (a) S. Kato, F. Diederich, Chem. Commun. 2010, 46, 1994-2006; (b) B. Breiten, Y.-L. Wu, P. D. Jarowski, J.-P. Gisselbrecht, C. Boudon, M. Griesser, C. Onitsch, G. Gescheidt, W. B. Schweizer, N. Langer, C. Lennartz, F. Diederich, Chem. Sci. 2011, 2, 88-93; (c) T. Michinobu, Chem. Soc. Rev. 2011, 40, 2306-2316; (d) M. Morimoto, K. Murata, T. Michinobu, Chem. Commun. 2011, 47, 9819-9821; (e) T. Shoji, J. Higashi, S. Ito, T. Okujima, M.

25 Yasunami, N. Morita, Chem. Eur. J. 2011, 17, 5116-5129; $(f)$ T. Shoji, S. Ito, T. Okujima, N. Morita, Eur. J. Org. Chem. 2011 , 5134-5140; $(g)$ T. Shoji, J. Higashi, S. Ito, T. Okujima, M Yasunami, N. Morita, Org. Biomol. Chem. 2012, 10, 2431-2438. 